\title{
Trabalhadores bancários em sofrimento: Uma análise da literatura nacional
}

\author{
Bank workers in distress: A national literature analysis \\ Sufrimiento de trabajadores bancarios: Un análisis de la literatura nacional
}

\author{
Gabriela da Silva MARQUES ${ }^{1}$ \\ Carmem Regina GIONGO \\ Universidade Feevale, Novo Hamburgo, RS, Brasil
}

Resumo

Este artigo tem como objetivo realizar uma revisão da literatura nacional dos últimos dez anos a fim de descrever as vivências de sofrimento de trabalhadores bancários no Brasil e as estratégias de intervenção utilizadas em face destas vivências. Trata-se, portanto, de um estudo teórico realizado entre os meses de junho e setembro de 2015 que pesquisou artigos de maneira sistemática na base de dados da Biblioteca Virtual em Saúde - Psicologia Brasil (BVS-Psi Brasil). Dentre os estudos analisados, identificou-se que a insegurança, as pressões de superiores, o assédio moral e as lesões por esforços repetitivos são algumas das principais vivências de sofrimento desta categoria profissional. Apesar de limitados, os serviços de apoio identificados estavam relacionados às parcerias feitas entre sindicatos bancários e universidades regionais. No que se refere às ações realizadas pelas agências bancárias, foram identificadas atividades físicas e ações de prevenção de lesões por esforços repetitivos. Concluiu-se que o atual cenário vivenciado pelos trabalhadores do segmento bancário no Brasil é precário e tem atuado diretamente na intensificação do sofrimento e do adoecimento destes profissionais.

Palavras-chave:

Sofrimento; saúde mental; saúde ocupacional.

\section{Abstract}

This article's objective is to perform a national literature review of the last ten years in order to describe the suffering experience of bank employees in Brazil and the coping strategies employed when dealing with this experience. Thus this is a theoretical study conducted from June to September 2015 that researched articles in a systemic way on the Virtual Library database in Health - Brazil Psychology (BVS-Psi). Among the studies analyzed, it was identified that insecurity, pressure exerted by superiors, mental harassment, and repetitive strain injury are among the most common experiences of suffering that bank workers have to face. Although limited, the support services that were identified were related to partnerships between bank labor unions and regional universities. Regarding the actions taken by bank branches, it was observed that they were limited to physical activities and repetitive strain injury prevention actions. It can be concluded that the actual setting that bank employees in Brazil currently experience is precarious and has directly contributed to the intensification of suffering and ultimately, caused illnesses among these professionals.

Keywords:

Suffering; mental health; occupational health.

Este artículo tiene como objetivo realizar una revisión de la literatura nacional de los últimos diez años con el fin de describir las experiencias de sufrimiento de los trabajadores bancarios en Brasil y las estrategias frente a estas experiencias. Se trata, por lo tanto, de un estudio teórico realizado entre los meses de junio y septiembre 2015, que investigó los artículos de manera sistemática con base en los datos de la "Biblioteca Virtual em Saúde - Psicologia Brasil (BVS-Psi)”. Entre los estudios analizados, se encontró que la inseguridad, las presiones de los jefes, el acoso moral y las lesiones por esfuerzo repetitivo, son algunos de las principales experiencias de sufrimiento de esta categoría profesional. Aunque limitados, los servicios de apoyo identificados estaban relacionados con las asociaciones hechas entre los sindicatos bancarios y universidades regionales. Con respecto a las acciones e realizadas por las agencias bancarias, fueron identificadas actividades físicas y acciones de 
prevención de lesiones por esfuerzo repetitivo. Se concluyó que la situación actual que viven los trabajadores de segmento bancario en Brasil es precaria y ha contribuido directamente a la intensificación del sufrimiento y a la enfermedad de estos profesionales.

Palabras-clave:

Sufrimiento; salud mental; salud ocupacional.

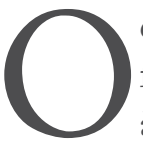

cenário que expressa o processo de saúde e adoecimento do trabalhador tem sofrido constantes transformações relacionadas às novas modalidades de trabalho, à dinamização dos processos produtivos, às inovações tecnológicas e às atuais estratégias de organização e gestão do trabalho (Mendes \& Wunsch, 2011). Essas demandas, advindas do processo de acumulação capitalista, "centradas na fratura das alteridades do trabalho" (Mota \& Amaral, 2000, p. 30), acabam fragmentando os coletivos de trabalho e a saúde mental dos trabalhadores expostos aos impactos da crise econômica.

Corrobora esses dados o último informativo da Organização Internacional do Trabalho (OIT), que aponta claramente profundas transformações do trabalho, justamente em um momento em que a economia global está deixando de criar novos empregos. Estima-se que o desemprego global tenha atingido 201 milhões de pessoas em 2014, 30 milhões a mais do que o período que antecedeu a crise global em 2008. Além disso, as projeções indicam que o desemprego crescerá consideravelmente nos próximos períodos, diante de 40 milhões de novos trabalhadores que ingressarão no mercado de trabalho global a cada ano (OIT, 2015).

Conforme dados da OIT, anualmente 2,02 milhões de pessoas morrem por enfermidades relacionadas ao trabalho, 321 mil pessoas morrem por acidentes no trabalho, 160 milhões de pessoas sofrem de doenças relacionadas ao trabalho e ocorrem 317 milhões de acidentes laborais. Não obstante, a cada 15 segundos um trabalhador morre por acidentes ou doenças relacionadas ao trabalho e, nesse mesmo intervalo de tempo, 115 trabalhadores sofrem um acidente laboral (OIT, 2015). Atualmente, dos 166,4 mil auxílios-doença concedidos pelo Instituto Nacional do Seguro Social (INSS), cerca de 15,2 mil são por problemas mentais ou comportamentais. A depressão está no topo, com mais de 5,5 mil casos, entre episódios depressivos ou transtornos recorrentes (Ministério da Previdência Social [MPS], 2014). Nesse sentido, o MPS (2014) afirma que as causas de afastamento do trabalho estão mudando drasticamente no Brasil. O último Boletim Informativo Quadrimestral sobre Benefícios por Incapacidade apontou que as doenças motivadas por fatores de riscos ergonômicos e sobrecarga mental têm sido as principais causas de afastamento do trabalho. Nos últimos 12 anos, as doenças motivadas por esses fatores têm superado os fatores de risco traumáticos (MPS, 2014).

Os bancários fazem parte de uma das categorias profissionais que mais adoece no Brasil, com elevados riscos de acidentes de trabalho e doenças ocupacionais, segundo a Central Única dos Trabalhadores (CUT, 2014). Uma pesquisa com nove mil profissionais da área, realizada pelo Sindicato dos Bancários e Financiários de São Paulo, Osasco e Região, revelou que 65\% dos entrevistados sentiam-se estressados e que 84\% deles tinham problemas de saúde (Associação de Pessoal da Caixa Econômica Federal [APCEF], 2011). Somente no ano de 2013, mais de 18 mil bancários foram afastados de suas atividades profissionais, sendo 24,6\% por Lesões por Esforços Repetitivos/Distúrbios Osteomusculares Relacionados ao Trabalho (LER/DORT) e 27\% por transtornos mentais e comportamentais, como estresse, depressão e síndrome do pânico (MPS, 2014). Sabe-se que os bancários se encontram predispostos a doenças, violências, sofrimentos psíquicos e pressões de superiores, estando sujeitos a sofrer consequências psíquicas referentes a esses eventos traumáticos (Lima, 2004). Além disso, os locais de trabalho onde há grande movimento de pessoas e constante circulação de dinheiro expõem os trabalhadores a um alto risco de assalto, o que aumenta a tensão e os níveis de ansiedade no trabalho (Schneider \& Werlang, 2013).

Nas bases destes indicadores estão as transformações ocorridas na organização do trabalho bancário no Brasil. Segundo Larangeira (1997), em meados dos anos 1970, houve uma grande transformação no setor. Anteriormente, a gestão e o modo de funcionamento eram definidos conforme critérios de cada agência bancária, que atuava de maneira não interligada. Os bancos organizavam-se de forma polarizada, sendo que a execução das atividades de trabalho era feita de forma taylorizada e as funções comerciais eram restritas à intermediação e à gestão financeira. $\mathrm{Na}$ maioria das instituições, os trabalhadores bancários eram avaliados conforme critérios de tempo de empresa e experiências profissionais adquiridas. O trabalho interno era conduzido de forma hierárquica, com pouca mobilidade, e valorizava-se sempre o tempo de atuação de cada trabalhador. 
Após a transformação dos anos 1970, várias mudanças ocorreram na organização do trabalho desse segmento. Os "trabalhadores experientes" (geralmente pessoas mais velhas) perderam a qualificação, pois sofreram dificuldades de adaptação ao novo modelo implantado. Com a inserção de novas tecnologias, como softwares e ferramentas eletrônicas, era preciso ter também conhecimento sobre assuntos como área de vendas, campo do mercado e matemática financeira. Os bancos passaram a trabalhar de forma múltipla, interligados por meio de redes bancárias (Larangeira, 1997). Nesse período, foram oferecidos programas de treinamento e de formação aos funcionários das agências e houve também a disponibilização de cursos rápidos de matemática financeira, crédito e serviços bancários em geral, informática, uso de softwares e aplicativos e simulações de negócios. As áreas de recursos humanos, por meio de novas ferramentas de gestão de pessoas, passaram a estimular fortemente diferenciais comportamentais nos trabalhadores, destacando-se o desenvolvimento de liderança, a tomada de decisão e a comunicação (Larangeira, 1997).

Conforme Araújo, Cartoni e Justo (2001), a reestruturação do sistema bancário brasileiro acentuou-se nos anos 1980, quando o país passou por uma forte crise econômica, vivenciando altos índices de desemprego. Na época, os bancos tiveram lucros significativos devido à alta inflação, o que facilitou o investimento em automação, que ocorreu em todo o setor. Assim, na década de 1990, difundiram-se as agências online, os caixas eletrônicos, os bancos 24 horas e os caixas automáticos, tornando o setor bancário brasileiro líder no quesito de incorporação de novas tecnologias e inovações organizacionais. Mas essas transformações não ocorreram somente no nível de informatização, houve também mudanças estruturais que modificaram os produtos de venda, o mercado de trabalho e as organizações internas. Além disso, no mesmo período, houve o processo de desregulamentação, no qual foi liberado às empresas não bancárias a operação no mercado de capitais. Esse processo retirou dos bancos a exclusividade das operações de crédito alterando estratégias comerciais, financeiras e de gestão (Larangeira, 1997; Silva \& Navarro, 2012).

Além disso, diante da expansão da concorrência, do processo de privatização e do aumento da inflação, as instituições bancárias deixaram de representar garantia de lucro. Consequentemente, os bancos focaram na segurança e no serviço de boa qualidade, procurando desenvolver estratégias para reduzir gastos e captar clientes, evitando o risco de falência. Em função dessas transições, várias agências foram fechadas nesse período (Araújo et al., 2001). Portanto, a reestruturação do setor refletiu-se diretamente no ambiente de trabalho. Elementos como a alta competitividade interna, o individualismo, o foco no cliente e no aumento constante da lucratividade passaram a caracterizar o trabalho bancário. Afinal, o trabalhador passou a ser incitado constantemente a cumprir as metas estabelecidas, buscando evitar demissões e sobreviver ao intenso ritmo de trabalho (Santos, 2009).

Após essas transformações no setor bancário, Maciel et al. (2006) realizaram uma pesquisa com 2.609 bancários de todo o Brasil, que apontou resultados inquietantes referentes à saúde desses trabalhadores. No estudo, destaca-se o percentual de $60,72 \%$ de respostas positivas no item "sentir-se nervoso, tenso e preocupado". No quesito "distúrbios de sono" também se nota um resultado significativo, sendo que 42,14\% dos participantes relataram passar por esse tipo de disfunção. Esses dados não surpreendem se contextualizados em um ambiente de trabalho caracterizado pela ocorrência de constantes humilhações, pelas reclamações de gestores e clientes, pelo estabelecimento de metas exacerbadas, pelas inúmeras vivências de assédio moral, pelas dores crônicas, pelas ameaças constantes de perda do emprego e pela individualização e dissolução dos coletivos de trabalho. É diante disso que o trabalhador teme não ser capaz de realizar seus deveres, o que gera incertezas em relação ao seu futuro, além de um profundo sofrimento psíquico que leva ao adoecimento físico e mental (Junior, Mendes, \& Araujo, 2009; Linhares \& Siqueira, 2014; Paparelli, 2011; Resende \& Mendes, 2004; Santos, 2009; Soares \& Villela, 2012).

Apesar disso, raras têm sido as estratégias de intervenção ou transformação apresentadas pelas instituições bancárias. Segundo Murofuse e Marziale (2001), devido ao alto índice de pessoas diagnosticadas com LER, algumas agências disponibilizam espaço para seus trabalhadores realizarem rápidas ginásticas e alongamentos (principalmente exercícios para pulsos, braços e pescoço) durante o expediente. Também há, em alguns locais, trocas de funções e rodízios de equipamentos. Essas atitudes são tomadas pelo banco na expectativa de que o trabalhador resista por mais tempo ao ritmo de trabalho, o que evitaria futuros afastamentos (Murofuse \& Marziale, 2001).

Diante desse preocupante contexto e do panorama atual de pesquisas acerca da temática no Brasil, este estudo tem o objetivo de descrever as vivências de sofrimento de trabalhadores bancários no Brasil e as estratégias 
de intervenção utilizadas frente a essas vivências. Além disso, buscou-se delinear quais são os serviços de apoio oferecidos pelas agências bancárias ou aqueles que são disponibilizados por meio de políticas públicas para os trabalhadores que se encontram em sofrimento e/ou adoecimento.

\section{MÉTODO}

Primeiramente foi realizada uma análise das bases de dados nacionais capazes de oferecer resultados consistentes e atualizados no campo da Psicologia e, com isso, escolheu-se a Biblioteca Virtual em Saúde Psicologia (BVS-Psi). O critério de escolha dessa fonte ocorreu por ser considerada a mais abrangente entre as disponíveis até o momento e por agregar fontes consistentes de dados científicos. A BVS-Psi faz a indexação de teses, monografias, textos didáticos, Index Psi Livros, LILACS, PePSIC e SciELO, e permite realizar serviços de comutação e consulta a catálogos de periódicos nacionais. Dentre as opções foram selecionadas as bases LILACS, PePSIC e SciELO, por apresentarem um maior número de materiais e atenderem aos critérios de inclusão deste estudo.

A consulta à base de dados empreendida para este artigo ocorreu no período de junho de 2015 a setembro de 2015. A busca dos artigos na BVS-Psi foi realizada por meio do descritor bancários, palavra que contempla a temática e que apresentou o maior número de documentos. Na sequência foram acessadas separadamente as fontes SciELO, PePSIC e LILACS e realizou-se uma primeira triagem manual, considerando-se o período de publicação e a nacionalidade dos estudos. Foram utilizados como critério de inclusão: o período (artigos publicados entre 10 de agosto de 2005 e 10 de agosto de 2015); a nacionalidade (estudos realizados no Brasil); e o conteúdo (vivências de sofrimento e/ou estratégias de intervenção e/ou serviços de apoio oferecidos aos bancários em sofrimento). Como critérios de exclusão foram utilizados: ausência de texto completo, artigos repetidos entre as bases ou na própria base, estudos internacionais, estudos que não contemplam a temática proposta e estudos fora do período estipulado.

Diante dos resultados obtidos nas buscas, realizou-se a leitura dos títulos, dos resumos e, em alguns casos, dos textos completos. Foram identificados 144 trabalhos nas buscas iniciais. Destes, 3 foram excluídos devido à nacionalidade, pois não estavam de acordo com a buscada, 21 foram descartados por estarem em mais de uma base, 42 foram eliminados devido ao conteúdo e 51 foram excluídos por estarem fora do período estipulado para a análise. Portanto, apenas 27 foram aproveitados. Os títulos aproveitados encontram-se registrados na Tabela 1. 
TABELA 1. Estudos selecionados e analisados

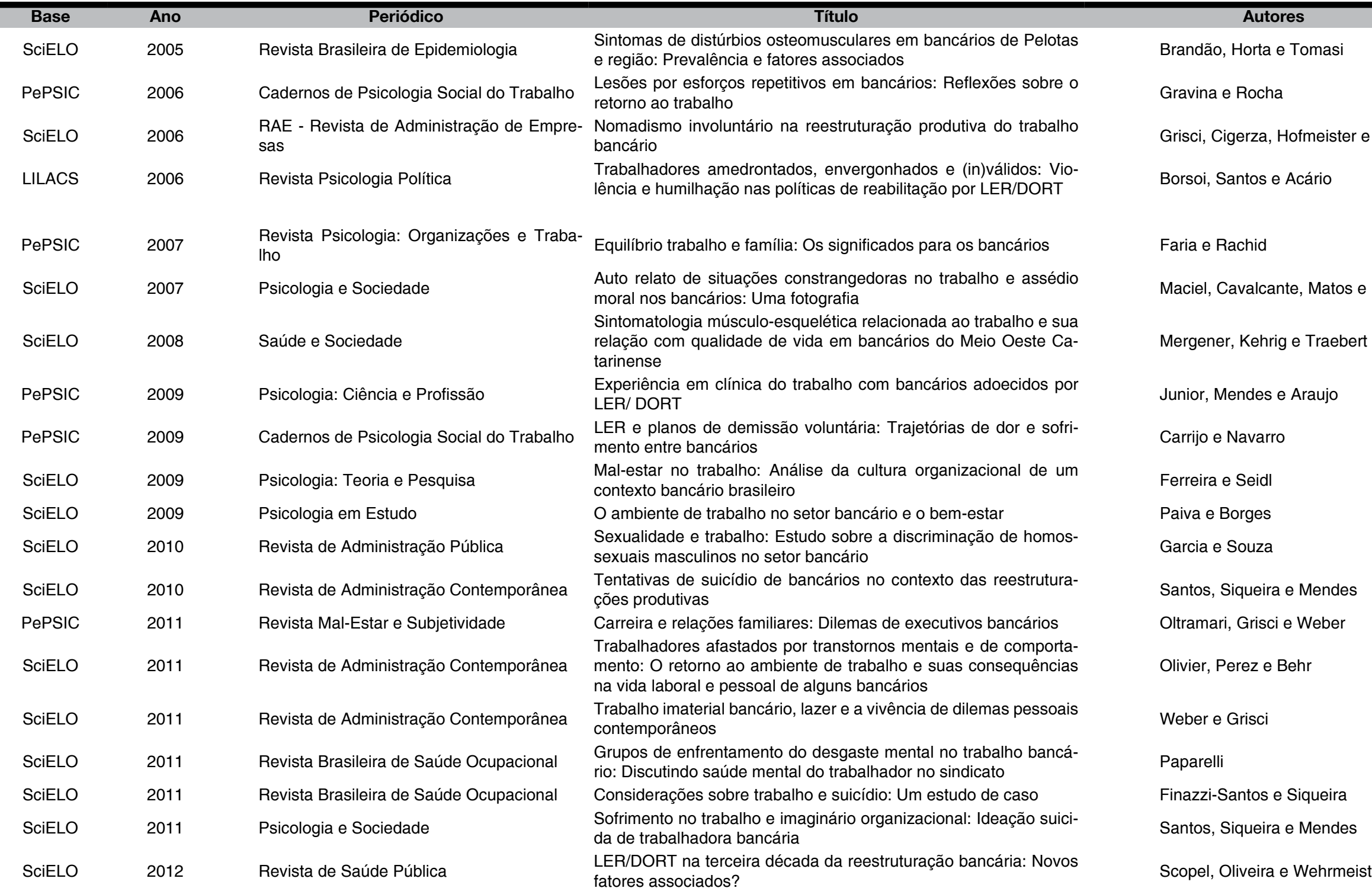


SCIELO

SCIELO

SciELO

201

SciELO

2012

LILACS

2013

Revista de Saúde Pública

Revista Latino-Americana de Enfermagem

Revista Brasileira de Saúde Ocupacional

Psicologia e Sociedade

Salud de los Trabajadores

SciELO

2014

Cadernos EBAPE.BR

SciELO

Cadernos de Saúde Pública
Condições estressantes no trabalho e pior auto avaliação de saúde entre bancários

Organização do trabalho e saúde de trabalhadores bancários

O assédio moral na perspectiva de bancários

Uma análise sobre as políticas de diversidade promovidas por ban-

La lucha de los sindicatos de bancarios de Brasil contra el acoso moral

Vivências depressivas e relações de trabalho: Uma análise sob a ótica da psicodinâmica do trabalho e da sociologia clínica

Auto avaliação do estado de saúde e fatores associados: Um estudo em trabalhadores bancários

\section{Silva e Barreto}

Silva e Navarro

Soares e Villela

Souza, Silva e Carrieri

Pavão

Linhares e Siqueira

Petarli, Salaroli, Bissoli e Zandonade 
Um exemplo entre os materiais excluídos por assunto é o artigo intitulado Relação entre concentração e rentabilidade no setor bancário brasileiro (Dantas, Medeiros, \& Paulo, 2011), que aborda assuntos administrativos-financeiros relacionados aos bancos nacionais. De modo geral, os materiais excluídos tratavam de assuntos como estratégias de gestão, finanças, responsabilidade social, marketing, captação de clientes, treinamento e desenvolvimento, segurança pública, avaliação física, entre outros.

A análise qualitativa dos 27 estudos selecionados foi realizada por meio das seguintes etapas: empreendimento de uma primeira leitura detalhada de cada artigo, com o intuito de compreender o objetivo, o delineamento e os resultados; realização de uma segunda leitura focada apenas nos resultados de cada investigação; agrupamento e categorização dos resultados conforme as temáticas propostas por este estudo; e, finalmente, descrição de cada categoria com apresentação dos resultados das pesquisas analisadas. Assim, os resultados obtidos serão apresentados em três eixos principais: (a) Apresentação e caracterização geral dos estudos, (b) Vivências de sofrimento e (c) Estratégias de intervenção frente ao sofrimento.

\section{RESULTADOS}

\section{Apresentação e caracterização geral dos estudos}

Diante das análises realizadas, observa-se que a temática tem sido publicada por periódicos situados em diferentes áreas do conhecimento, como no campo da Psicologia, da Administração, da Saúde Pública, da Saúde Ocupacional e da Enfermagem. Elemento que aponta para a relevância e complexidade do assunto. Quanto aos objetivos principais dos estudos, os temas mais investigados nos últimos dez anos são os transtornos musculoesqueléticos e os efeitos da reestruturação produtiva sobre os trabalhadores. Sendo assim os objetivos puderam ser agrupados em: prevalência de LER/DORT, intervenção clínica e retorno ao trabalho após afastamento em função dessa patologia (7); consequência da reestruturação produtiva (5); assédio moral e/ou violência (2); discriminação homossexual (2); condições de trabalho e estado de saúde (2); suicídio e trabalho bancário (2); carreira e relações familiares (1); retorno ao trabalho após afastamento por adoecimento mental (1); trabalho imaterial (1); relato de experiência de intervenção com sindicato e psicologia (1); depressão e trabalho bancário (1); mal-estar e ambiente de trabalho (1); bem-estar e ambiente de trabalho (1).

Quanto à metodologia empregada, 18 estudos contaram com delineamento qualitativo (por meio de entrevistas individuais e grupos), 9 estudos utilizaram delineamento quantitativo (aplicação de questionário ou inventário) e 1 estudo fez uso de delineamento misto (utilização de inventário e entrevistas). É interessante destacar que os estudos qualitativos podem representar um espaço de acolhimento e escuta aos trabalhadores em sofrimento, servindo como estratégia de apoio e ressignificação dos processos de trabalho, enquanto as pesquisas quantitativas contribuem para o acesso a um número elevado de bancários, possibilitando um panorama geral do estado de saúde e adoecimento dessa categoria profissional.

\section{Vivências de sofrimento}

A análise realizada a partir dos estudos selecionados permitiu mapear as principais vivências de sofrimento dos bancários investigados no Brasil nos últimos dez anos. Dentre elas merecem destaque: (a) a precarização do trabalho, quando os bancários são induzidos ao individualismo e à solidão; (b) o assédio moral, que ocorre com muita frequência, torna o ambiente de trabalho destrutivo e desgasta psiquicamente o trabalhador; (c) o sentimento de perda de identidade, quando o trabalhador perde sua capacidade de fala e não pode manifestar seus desejos, que o leva a agir contra seus princípios éticos e morais; (d) as doenças de ordem física por esforço repetitivo, apontadas como causa de muitos problemas da saúde no trabalho; (e) a discriminação e o sofrimento dos trabalhadores adoecidos, especialmente daqueles diagnosticados com LER ou DORT; (f) a escassez de direitos civis aos homossexuais; (g) a presença de depressão e risco de suicídio; e (h) os sentimentos constantes de insegurança, frustração, pressão psicológica, ansiedade, medo e angústia.

Além disso, os bancários consideram sua atividade profissional responsável pelos constantes conflitos familiares, de forma que ela chega a interferir em momentos de descanso e lazer pessoal (Borsoi, Santos, \& Acário, 2006; Brandão, Horta, \& Tomasi, 2005; Faria \& Rachid, 2007; Finazzi-Santos \& Siqueira, 2011; Gravina \& Rocha, 2006; Junior et al., 2009; Linhares \& Siqueira, 2014; Maciel, Cavalcante, Matos, \& Rodrigues, 2007; Paiva \& Borges, 2009; Santos, Siqueira, \& Mendes, 2011; Silva \& Navarro, 2012; Soares \& Villela, 2012; Souza, Silva, \& Carrieri, 2012). 
Conforme pesquisa realizada por Paparelli (2011), essas vivências de sofrimento estão diretamente associadas à organização do sistema bancário, caracterizada pela alta competitividade e pela sobrecarga de atividades dos trabalhadores. Dessa forma, os bancários se mostram vulneráveis diante de atividades complexas, que demandam altas cargas psicoafetivas e autocontrole emocional constantes. Além disso, a perfeição é exigida invariavelmente pelos superiores, as grandes responsabilidades são frequentes, as incertezas no que se refere à carreira e ao emprego fazem parte do cotidiano e as pressões para o cumprimento dos inúmeros prazos estipulados é diária.

Junior et al. (2009) relatam que muitas vezes o bancário precisa vender algo que nem mesmo ele compraria, o que o faz sentir-se antiético. Conforme apontado, "os trabalhadores superam valores pessoais para o alcance de metas impostas pela empresa” (Junior et al., 2009, p. 621). Em virtude disso, os bancários relatam sentir medo e humilhação, sendo frequentemente forçados a agir contra seus princípios éticos e morais. A renúncia dos desejos próprios do bancário, como ter de vender algo que ele não compraria e o fato de agir contra suas vontades em prol dos objetivos da instituição, são fatores que promovem a depressão no trabalhador. $\mathrm{Da}$ mesma forma, o isolamento social, o sentimento de não pertencer à comunidade em que trabalha, a falta de liberdade para falar e se expressar também são aspectos causadores de depressão. Patologia essa que surge também do individualismo, da competitividade, da humilhação, da cultura do narcisismo e da exaltação do eu, que é comum no contexto bancário (Linhares \& Siqueira, 2014; Paparelli, 2011).

Esses trabalhadores, inclusive, alegam que o ato de humilhar dentro da agência bancária é uma questão de poder e domínio. Segundo eles, quem pratica esse tipo de ato justifica-o em favor da produção, da busca pelo cumprimento das metas, resultados e lucros e da instituição financeira em geral. As humilhações, junto com o assédio moral, ocorrem de forma hierárquica, sendo que, normalmente, o profissional de nível superior perturba o trabalhador de nível inferior (Soares \& Villela, 2012). Alguns bancários tentam conversar com seus chefes para resolver os problemas que os incomodam, no entanto, raramente têm sucesso com os diálogos e é comum que as pressões e reclamações continuem ou piorem, pois há chefes que interpretam equivocadamente a queixa e, portanto, os problemas aumentam para o funcionário (Santos, 2009). Assim, em diversos momentos, a solidão torna-se desejo do trabalhador bancário, pois diante da situação de nunca dar conta do serviço e das metas que precisa cumprir, ele deseja ficar sozinho como mecanismo de defesa para "disfarçar" a desconfiança do próximo, a vergonha e a dor por suas frustrações, aumentando as chances do surgimento de depressão no trabalho (Linhares \& Siqueira, 2014).

Desse modo, são comuns os relatos associados ao assédio moral. Normalmente a prática do assédio não está necessariamente relacionada ao banco como organização de trabalho, mas ao responsável superior direto (Paparelli, 2011). Em pesquisa, Soares e Villela (2012) observam que o ataque moral também acontece entre colegas e afeta níveis hierarquicamente inferiores. $\mathrm{O}$ assédio moral tem destaque e se torna destruidor devido à repetição diária com que ocorre, o que desgasta a pessoa. Esse ato é caracterizado por ações que desvalorizam, humilham e diminuem o ser humano, como, por exemplo, pressões psicológicas, isolamento físico e psicológico, desrespeito, perseguição, ofensas e condutas que afetam o próximo. Trata-se de algo constante e diário que causa desgaste moral e psicológico no trabalhador, o deixando propenso a somatizações que podem desequilibrar sua saúde mental e física. Além disso, o assédio moral pode prejudicar o rendimento no trabalho e o ambiente que, consequentemente, se torna pesado. Alguns autores sugerem pensar o assédio moral como um problema coletivo e não somente individual (Santos, 2009; Soares \& Villela, 2012).

Na pesquisa conduzida por Maciel et al. (2007) com o objetivo de identificar e analisar a ocorrência de situações constrangedoras no trabalho, 2.609 bancários responderam a um questionário e identificou-se que as vítimas mais frequentes de assédio moral dentro das agências são as mulheres e os homossexuais ou bissexuais. Em face disso, Garcia e Souza (2010) realizaram um estudo com 10 bancários homossexuais masculinos a fim de analisar as possíveis formas de discriminação no ambiente de trabalho. Os autores identificaram como causadoras de maior incômodo para estes sujeitos as expressões de discriminação que ocorrem indiretamente no local de trabalho, manifestadas pelos colegas. Na maioria das vezes, elas ocorrem na forma de piadas que mostram os homossexuais de forma caricata e pejorativa. Observou-se que os entrevistados sentem falta de normativas dos bancos para garantir e esclarecer seus direitos, visto que alguns são unidos em casamento homoafetivo. Esse tipo de "falha" é considerada pelos bancários homossexuais como discriminação direta.

Outro fator de sofrimento recorrente está relacionado à preocupação diante das pressões psicológicas que ocorrem na instituição em busca do cumprimento de metas pré-estabelecidas. Acompanhado disso, surge a 
insegurança referente à área de atuação e, muitas vezes, o sentimento de frustração (Silva \& Navarro, 2012). Segundo Rocha (2007), os bancários sofrem tanto pressões internas como externas. As pressões internas surgem pelo receio de errar um cálculo e ter de reembolsar algum valor, pelos horários e pelas metas a serem cumpridas. Já as pressões externas, que o autor nomeia como "um bicho" para o trabalhador, são representadas pelas enormes filas de espera por atendimento. Essas pressões deixam o bancário angustiado e agitado, tentando terminar rapidamente com o acúmulo de pessoas, todavia, a atividade nunca termina e o dia de trabalho passa a ser conturbado. Segundo a autora, "o ambiente é descrito como pesado, deprimente, desencadeador de sofrimento, insônia e adoecimento” (Rocha, 2007, p. 209). Lima, Barbosa, Mendes e Patta (2014) depararam-se também com esta pressão de horários e metas que os bancários, especialmente os caixas, devem cumprir. É constatado que os caixas sofrem pressão com o tempo de atendimento dos clientes, já que o tempo de cada pessoa na fila não pode ultrapassar 25 minutos. Além disso, o operador do caixa deve vender serviços como seguros, débitos automáticos e planos de capitalização.

Essas incertezas são relativamente contemporâneas, pois surgiram a partir da década de 1990, quando houve a acentuada reestruturação financeira internacional e nacional na área bancária e passou-se a exigir maior produtividade e requalificação dos profissionais. Nesse momento, os trabalhadores mais velhos e com mais tempo de serviço ficaram em desvantagem. Algo que era considerado "para a vida toda" hoje está sujeito a mudanças, como as transferências de um banco para outro e/ou as transferências de cargo. Assim, a insegurança no trabalho aumenta, trazendo dúvidas na estabilidade do emprego e a ruptura dos laços de confiança.

Todas essas modificações do setor bancário causaram, consequentemente, grandes efeitos na relação entre saúde e trabalho no banco, pois notou-se um aumento do sofrimento mental do trabalhador. O profissional passou a se sentir sem identidade, além de haver o aumento das doenças físicas relacionadas à intensificação do trabalho, que ocorreu após a reestruturação (Grisci, Cigerza, Hofmeister, \& Becker, 2006; Junior et al., 2009; Scopel, Oliveira, \& Wehrmeister, 2012; Silva \& Navarro, 2012). Foi observado que, após esse momento de reorganização bancária, o Plano de Demissão Voluntário (PDV) passou a ser mais utilizado como instrumento de pressão junto aos trabalhadores. Além disso, o trabalhador precisou lidar com a sobrecarga corporal para contornar o medo e a ansiedade diante das promessas simbólicas feitas pela organização (Carrijo \& Navarro, 2009; Junior et al., 2009).

Em um estudo de caráter exploratório com 15 sujeitos inseridos no Banco Múltiplo Privado, Weber e Grisci (2011) constataram algumas ligações entre o trabalho e o lazer do bancário. Foram relatadas dificuldades em "se desligar" do banco no horário livre, sendo que o trabalhador relata que toda vez que o telefone toca, ele tem a sensação de que é uma ligação do trabalho. Mesmo sem levar atividades do banco para casa, o trabalhador permanece pensando o tempo todo em problemas da agência, chegando a ter insônia e falta de ânimo para comer. Nessa pesquisa, verificou-se inclusive que os trabalhadores desse banco costumam ter seus momentos de lazer prejudicados, devido às horas extras, às reuniões fora de hora e até no fim de semana, o que os impede de programar viagens e momentos com a família e os amigos. Eles também relataram sentir muitas preocupações com o trabalho e falta de tranquilidade nas férias.

Concluiu-se, no estudo, que há um grande dilema causador de sofrimento entre o trabalho e o prazer: quem opta pelo prazer é descrito como vagabundo, sem coleguismo, desleixado e louco; por outro lado, quem só trabalha é visto como fominha, corinho, realista e bajulador. Diante disso, o sujeito encontra-se sem uma saída favorável, pois ou é tido como egoísta por seus familiares porque só trabalha, ou é tido como descomprometido pelo banco, caso opte pelo lazer. Alguns autores apontam o trabalho como a causa mais frequente de conflitos nas relações familiares do bancário (Faria \& Rachid, 2007; Oltramari, Grisci, \& Weber, 2011).

Santos (2009), que teve como objetivo em sua pesquisa avaliar a organização do trabalho como um dos fatores responsáveis pelo suicídio de bancários, identificou que as situações mais estressantes para esses trabalhadores podem ser as convivências artificiais entre colegas, muito ou pouco trabalho, pouco reconhecimento pelas atividades executadas, desqualificações frequentes e gestores autoritários. Santos, Siqueira e Mendes (2010) identificaram a organização de trabalho como um dos principais fatores diante da decisão pela tentativa de suicídio de seus pesquisados. Os participantes do estudo relataram vivenciar muitas experiências negativas relacionadas ao ambiente de trabalho. Além disso, alegaram que pequenas mudanças na "mentalidade" dos administradores em relação a limites éticos seriam o suficiente para impedir o adoecimento dos trabalhadores. Em um estudo de caso realizado pelos autores, o trabalho é apontado como o elemento mais importante e decisivo para cometer a tentativa de suicídio (Santos et al., 2011). 
Em contrapartida, em uma pesquisa com 200 bancários, foram identificadas mais evidências positivas do que negativas se referindo ao bem-estar do sujeito no seu local de trabalho. Os participantes da pesquisa relataram sentir-se competentes e com autonomia. Entretanto, no mesmo estudo, houve sinais de depressão e de tensão emocional em parte da amostra (44\%). Surgiu também uma proporção de pessoas insatisfeitas com a vida. Isso levou os autores a fazer uma relação dos resultados com estudos anteriores que alertam para o risco de depressão entre bancários (Paiva \& Borges, 2009).

Patologias como LER e DORT aumentaram drasticamente após a reestruturação produtiva, quando a categoria mais atingida foi a dos bancários (Rocha, 2007). Em uma pesquisa com 502 bancários de Pelotas (RS) e região, Brandão et al. (2005) verificaram que 60\% dos entrevistados mencionaram ter sentido dor musculoesquelética no último ano. Desses, $40 \%$ alegaram que a dor estaria ligada à sua função no trabalho. Em pesquisa, Gravina e Rocha (2006) também identificaram como uma das maiores dificuldades do bancário diagnosticado com LER a presença constante da dor. Além dessa, o sentimento de incapacidade e o preconceito em relação à doença também foram citados.

É visto que as novas tecnologias adotadas pelo banco, em 1990, trouxeram bastante lucro às instituições, no entanto, elas intensificaram o trabalho repetitivo para os funcionários, o que refletiu diretamente na sua saúde (Carrijo \& Navarro, 2009). Em pesquisa realizada com 263 bancários de 13 municípios da região do Meio Oeste Catarinense identificou-se um alto índice de sintomatologia musculoesquelética em 72,8\% dos entrevistados (Mergener, Kehrig, \& Traebert, 2008). Essa prevalência demonstrou afetar negativamente os sujeitos, prejudicando sua qualidade de vida psíquica, social e ambiental. Conforme Junior et al. (2009), dores físicas acompanhadas por ansiedade e depressão, com diagnóstico de difícil identificação, são características de LER/ DORT. Em relação a isso, Rocha (2007) realizou um estudo investigando a depressão após o adoecimento por DORT/LER. Nessa pesquisa, a autora percebeu que o trabalhador diagnosticado com DORT pode apresentar depressão em função das restrições que surgem na família e no trabalho. A depressão pode se apresentar durante a procura do diagnóstico definitivo, durante o tratamento ou até mesmo após seu diagnóstico.

No estudo realizado por Junior et al. (2009), os bancários sentem-se culpados pelo próprio adoecimento, visto que várias vezes não há reconhecimento social do adoecimento por lesões por esforços repetitivos. Considerados "desocupados" pela família, os participantes desse estudo relataram ter ficado responsáveis até pelas tarefas domésticas que ninguém tinha tempo para fazer, como, por exemplo, ir ao supermercado, transportar membros da família ou cuidar de crianças, o que fez com que se sentissem ainda mais tristes. No ambiente de trabalho, os adoecidos relataram sentir insinuações de seus colegas em atividade. Segundo eles, foram acusados de culpados pelo próprio adoecimento, de fugir de suas obrigações e de querer receber a remuneração sem trabalhar.

Paparelli (2011) expõe que o sentimento de culpa vivenciado por esses trabalhadores leva ao isolamento. Eles sentem-se envergonhados diante da situação, deixando de interagir com as outras pessoas a fim de evitar falar sobre o seu adoecimento. Carrijo e Navarro (2009) identificaram comprometimentos semelhantes aos de Junior et al. (2009), pois verificaram que as atividades fora do ambiente profissional também ficaram comprometidas, por exemplo, as atividades do lar, os cuidados pessoais, o momento de relaxar e o lazer. Essas práticas ficaram comprometidas por causa das dores sentidas em consequência de LER.

As tarefas inadequadas devido às sequelas da doença, o não oferecimento de intervalos durante o expediente, a obrigação de cumprimento de horas extras e as metas impossíveis de alcançar são algumas das dificuldades que o trabalhador afastado por LER sente no momento do retorno às atividades no banco. Além dessas, Gravina e Rocha (2006) identificaram uma grande dificuldade de relacionamento entre a equipe e o trabalhador que está retornando, que sente discriminação ou pressão por parte dos colegas e da chefia. Borsoi et al. (2006) relatam que a tentativa de reabilitação de bancários afastados por LER/DORT é desfavorável ao trabalhador que não recupera sua capacidade laborativa. Em sua pesquisa, consta que esse pode ser mais um fator desencadeante de sofrimento, que ocasiona o constrangimento e a humilhação do indivíduo. Como consequência, o sujeito se sente mais envergonhado e amedrontado por sua limitação, com sensação de inutilidade, sob risco de demissão.

Em uma pesquisa feita recentemente com 525 funcionários de uma rede bancária do estado do Espírito Santo foi identificada como maior causa negativa na saúde dos entrevistados ter uma ou mais doenças crônicas. Foi apontada também a falta de prática de exercícios físicos, o excesso de peso e a carência de apoio coletivo no ambiente de trabalho (Petarli, Salaroli, Bissoli, \& Zandonade, 2015). Todos esses resultados revelam, de 
fato, um cenário de intenso sofrimento, adoecimento e solidão do trabalhador bancário investigado no Brasil nos últimos anos.

\section{Estratégias de intervenção frente ao sofrimento}

Dentre os 27 estudos analisados, foram encontrados apenas três artigos com resultados relacionados às estratégias de intervenção e aos serviços de apoio oferecidos aos bancários em situação de sofrimento ou adoecimento relacionado ao trabalho. Essas estratégias podem ser resumidas em: reabilitação profissional oferecida pelo INSS, atividades físicas e ações de gestão de pessoas disponibilizadas pelas agências bancárias e programas de apoio organizados por universidades e sindicatos.

No que diz respeito ao trabalho desenvolvido pelo INSS, particularmente em Brasília, são organizados períodos de reabilitação profissional para trabalhadores bancários afastados por LER/DORT. O trabalho é realizado em parceria com a Universidade de Brasília e nele os estudantes de psicologia, com supervisão, formam grupos na tentativa de reinserir os profissionais afastados no mercado de trabalho. Normalmente essas pessoas são encaminhadas por sindicatos de bancários (Junior et al., 2009). Gravina e Rocha (2006) destacam que é de grande contribuição pessoal o retorno desses trabalhadores, pois a volta desperta nestes indivíduos o sentimento de inclusão social. E quando há apoio dos colegas de equipe, a motivação é maior.

Em uma pesquisa feita por Oliveira (2010) com trabalhadores da agência Pestanense do Banco Alfa, no interior do Rio Grande do Sul, identificou-se a aplicação de massagens nos funcionários da agência em intervalos quinzenais. Essa iniciativa surgiu a partir de reclamações dos bancários em virtude do ritmo intenso de trabalho, das poucas atividades alternadas e de passarem muito tempo sentados. Nesse estudo, os entrevistados também apresentaram como ponto positivo a realização de jantares e de reuniões informais envolvendo funcionários do banco e familiares. Os participantes da pesquisa relataram a grande importância dessas confraternizações entre colegas, por trazerem benefícios ao grupo, facilitando o convívio e melhorando o ambiente de trabalho e a rotina de todos.

Lima et al. (2014) observaram, em sua pesquisa em uma agência bancária, a presença de um quadro, como instrumento de auxílio para os trabalhadores exporem suas críticas e elogios aos seus colegas, superiores e a si mesmos. Diariamente ocorrem reuniões com "retornos" dos gestores, chamadas de momento de "dar e receber feedback”. Faria e Rachid (2007) encontraram como estratégia de enfrentamento do trabalhador bancário em face dos conflitos familiares a adoção de serviços de uma empregada doméstica. A ação teria reduzido os problemas familiares. Na pesquisa, é citada também a realização de atividades de lazer promovidas pelo banco. Da mesma forma, a redução do horário de trabalho é mencionada como positiva pelo trabalhador.

No que diz respeito à atuação sindical, é visto que estas organizações bancárias estão procurando auxílio nas universidades para desenvolver programas de apoio aos trabalhadores associados. Paparelli (2011) relata em seu artigo as experiências vividas em uma parceria do Sindicato dos Bancários de São Paulo, Osasco e Região e o curso de Psicologia da Pontifícia Universidade Católica de São Paulo (PUC-SP). Várias vivências são relatadas como fruto dessa parceria, como as pesquisas e as intervenções feitas com trabalhadores visando desmistificar questões de saúde mental relacionadas ao trabalho.

Ressalta-se a importância de um trabalho como esse, no qual o participante tem a oportunidade de entender seu processo de adoecimento e a relação disso com sua história de vida, considerando-se o momento de reestruturação produtiva atual. No grupo, os psicólogos auxiliaram na construção de estratégias de enfrentamento coletivas e individuais que os trabalhadores poderiam usar para aliviar seu sofrimento (Paparelli, 2011). Schneider e Werlang (2013) trazem em seu artigo estudos feitos pelo curso de Psicologia da Pontifícia Universidade Católica do Rio Grande do Sul (PUC-RS) em parceria com o Sindicato dos Bancários de Porto Alegre e Região. Por meio desses estudos, pode-se perceber o interesse de parcerias entre Sindicatos de Bancários e Universidades, buscando-se suporte para auxiliar os trabalhadores atuantes ou afastados do trabalho.

\section{DISCUSSÃO}

Diante do fenômeno da globalização, entendida também como a mundialização do capital (Chesnais, 1995) ou como a economia capitalista mundial (Wallerstein, 1987), os processos de trabalho nos mais diferentes segmentos passaram por importantes transformações, alterando diretamente as relações de trabalho, produção, consumo e ideais de progresso e de desenvolvimento das nações. No que concerne aos modelos de gestão e 
organização do trabalho, presenciou-se a inserção do toyotismo, cujas características principais são: procurar responder de forma mais ágil e eficiente possível às demandas do mercado, priorizar o trabalho em equipe e a multiplicidade de funções, proporcionar ao trabalhador que conheça e opere várias máquinas simultaneamente, aperfeiçoar o tempo de produção, organizar o processo para gerar estoque mínimo, trabalhar em uma estrutura mais horizontalizada, além de aproveitar o potencial intelectual dos trabalhadores (Antunes, 2011).

Ademais, o desafio do gerenciamento contemporâneo tornou-se justamente o de controlar e capturar os trabalhadores sem recorrer à lógica taylorista. A estratégia, então, foi a de transformar cada trabalhador em seu próprio gestor, ou então, em gestor do seu próprio colega, por meio da disponibilização de autonomia e das novas ferramentas de gestão de pessoas. Associado a isso, há ainda uma constante demanda pela melhoria dos processos de trabalho, pela inovação, pela mudança, pelo fazer melhor, pelas boas práticas, pelo alcance do lugar de destaque. A partir desta perspectiva surge o que Linhart (2015) chama de precarização subjetiva. Mesmo os trabalhadores mais estáveis são imersos nas constantes mudanças organizacionais, o que os faz perder as referências e os conhecimentos já construídos. A precarização subjetiva coloca o trabalhador em um estado de vulnerabilidade e de não-saber (Linhart, 2015).

Corroborando esta discussão, Alves (2013) afirma que o toyotismo associado à vigência do capitalismo manipulatório conquistou de maneira muito eficaz uma nova forma de subjetivação da força de trabalho. Assim, a lógica de produção e de manipulação que nasceu na produção flexível se disseminou nas práticas de trabalho, demandando não apenas da força humana ou do corpo, mas do engajamento da personalidade e da subjetividade do trabalhador. Diante disso, a instabilidade, o desemprego e a flexibilidade das novas formas de contratação e de remuneração atuaram diretamente na relação do homem com seus semelhantes e também consigo mesmo.

A análise dos estudos realizados nos últimos dez anos no Brasil acerca do trabalhador bancário revela os efeitos destes processos sobre a saúde destes profissionais. As transformações ou inovações tecnológicas e de gestão, associadas ao movimento de flexibilização das relações de trabalho, privatização das instituições bancárias, desregulamentação do mercado financeiro, globalização da economia, aumento da concorrência, redução de custos, terceirização da mão-de-obra e aumento dos índices de desemprego, são apontados como elementos chave no processo de intensificação do sofrimento, adoecimento e morte desses trabalhadores (Junior et al., 2009; Linhares \& Siqueira, 2014; Paparelli, 2011; Resende \& Mendes, 2004; Santos, 2009; Silva \& Navarro, 2012; Soares \& Villela, 2012). Diante disso observa-se uma descaracterização do trabalho bancário, antes visto como sinônimo de estabilidade e visibilidade social (Larangeira, 1997).

A redução do papel e atuação do sindical também surge como efeito dessa reconfiguração, atrelada ao medo da demissão e a diminuição do contingente trabalhista, elementos que atuam na fragilização da mobilização coletiva e na redução de respostas diante dos fatores geradores de sofrimento. A partir disso, é possível compreender as inúmeras e intensas experiências de sofrimento e de adoecimento vivenciadas pelos bancários investigados pelos estudos brasileiros aqui descritos.

Percebe-se que elementos como o ritmo de trabalho, as pressões pelas metas estabelecidas e os estressores provenientes da natureza da atividade neste segmento são intensificados pela precarização conjuntural das relações e da organização do trabalho, levando ao adoecimento físico e mental e, em alguns casos, ao suicídio. O trabalho bancário apresentado pelas pesquisas realizadas aparece sozinho, adoecido e com uma frágil rede de apoio e de proteção (Linhares \& Siqueira, 2014; Paparelli, 2011; Pavão, 2013; Silva \& Navarro, 2012). Linhart (2015) discute este fenômeno abordando também a transformação do sentido do trabalho. O trabalho que anteriormente era um lugar de cidadania, direitos e deveres, legitimidade, experiência coletiva e espaço social, se transformou em um lugar de valorização de si, realização própria e conquista do sucesso individual. Atualmente, segundo o autor, é no trabalho que o homem moderno busca mostrar o quanto é bom e melhor do que os outros. E essa transformação acarreta os principais elementos do sofrimento no trabalho: a solidão e o individualismo. Por meio disso, o trabalhador tende a interiorizar suas dificuldades como uma questão individual.

Na perspectiva de Alves (2013), esse modo de produção culmina na captura da subjetividade, que está na base da dissolução do coletivo de trabalho e no surgimento de equipes conhecidas como colaborativas, que incorporam as ideias e os ideais da empresa como se fossem suas próprias ideias e ideais. A partir disso é que se concebe o trabalhador bancário como "pequenas pétalas sobre o mar em grandes marés" (Linhart, 2015, p. 22). Essa analogia, cunhada por Linhart (2015), está na base conceitual do atual cenário do trabalho, no qual 
o trabalhador, cada vez mais individualizado, é confrontado sozinho por estratégias de gestão que capturam não só o corpo, como também a subjetividade, a identidade e os coletivos de trabalho. Isso interfere até nas relações familiares, de lazer e de convivência social fora do campo profissional, conforme apontado por alguns dos artigos analisados.

É neste contexto que os estudos analisados apontam claramente o desamparo dos trabalhadores bancários diante da organização do trabalho. Em face do sofrimento, em alguns casos, esses profissionais ainda conseguem buscar a assistência junto aos sindicatos que representam a categoria. No entanto, o apoio junto às agências bancárias e aos próprios colegas de trabalho parece não existir. Do mesmo modo, foi constatada escassez nos programas organizados pelas instituições para amparar as necessidades de seus trabalhadores. Também não foram encontrados estudos ou relatos de planejamentos de projetos com a finalidade de oferecer apoio aos trabalhadores em situações de sofrimento e/ou adoecimento.

São raras as pesquisas que abordam as atividades e os programas disponibilizados pelos bancos para dar suporte aos bancários. Diante do preocupante cenário descrito neste artigo, cabe salientar a demanda de pesquisas ou projetos que ofereçam não apenas apoio a esses trabalhadores fora do ambiente de trabalho, mas possam pensar em conjunto a organização do trabalho, as práticas de gestão e as relações de trabalho. Cabe destacar que nos artigos pesquisados, as iniciativas relatadas pelas agências bancárias possuíam como ênfase a saúde física dos seus funcionários, sendo que algumas disponibilizaram a chance de o funcionário relaxar seus pulsos, braços e pescoço, com o propósito de prevenir futuros atestados médicos e afastamentos causados por esforços repetitivos. Estratégias essas que, se utilizadas isoladamente, nada mais fazem do que adaptar o trabalhador aos fatores geradores de sofrimento e adoecimento provenientes da organização do trabalho. Além disso, grande parte dos estudos realizados nos últimos anos objetivaram investigar os transtornos musculoesqueléticos, como se o adoecimento estivesse dissociado da reestruturação produtiva e do sofrimento mental.

Observa-se que, na atual conjuntura, além das vivências de precarização subjetiva e do trabalho, os bancários que adoecem ou que demonstram resistência ao atual modelo de gestão empregado, são culpabilizados ou tratados isoladamente, fora do ambiente de trabalho. Ações como essas, que deixam de intervir no contexto gerador de sofrimento e adoecimento (nesse caso, na organização do trabalho bancário) nada mais fazem do que adaptar o trabalhador para que continue, por mais algum tempo, cumprindo suas metas e prazos, mesmo que adoecido eticamente, moralmente, psicologicamente e fisicamente.

Este estudo apontou que as principais vivências de sofrimento descritas pelas pesquisas nacionais realizadas nos últimos anos com bancários estão relacionadas à precarização geral do trabalho, à precarização subjetiva, à solidão e ao individualismo, às fortes pressões, ao ritmo de trabalho e às violências éticas e morais. Esse contexto, gerado pelas práticas de gestão e pela reestruturação da organização do trabalho, leva às patologias da sobrecarga, como LER / DORT, à depressão e até mesmo ao suicídio. Diante disso, as estratégias de enfrentamento e os serviços de apoio oferecidos a esses trabalhadores se resumem a ações de reabilitação profissional oferecidas pelo INSS, atividades físicas e ações de gestão de pessoas disponibilizadas pelas agências bancárias e pelos programas de apoio organizados por universidades e sindicatos. Observou-se que a priori essas ações realizam intervenções individualizadas, fora do ambiente de trabalho, ou com trabalhadores já afastados de suas atividades profissionais. Do ponto de vista das agências bancárias, os projetos parecem focados exclusivamente na adaptação dos trabalhadores aos fatores de gestão geradores de sofrimento e adoecimento, e não na real problematização da organização do trabalho.

Assim, diante dos objetivos propostos por este estudo, destaca-se a necessidade de desenvolvimento de programas e de políticas públicas com foco na saúde mental do trabalhador bancário. Cabe também a problematização do papel das instituições bancárias-financeiras em virtude da crescente intensificação do sofrimento e do adoecimento da categoria no Brasil. Como o foco dessa revisão esteve pautado no mapeamento das categorias sofrimento no trabalho, estratégias de enfrentamento e serviços de apoio oferecidos, sugere-se que novos estudos sejam realizados buscando levantar outros importantes dados, como, por exemplo, metodologias utilizadas por esses estudos, revistas com maior publicação na temática, universidades com maior incidência de pesquisas, resultados gerais das investigações e áreas que investigam a categoria. Além disso, sugere-se a ampliação desse estudo por meio de uma pesquisa comparativa entre resultados de artigos nacionais e internacionais, ou mesmo por meio da busca por teses e dissertações brasileiras.

Finalmente, este trabalho contribuiu por apresentar um apanhado geral das experiências dos trabalhadores bancários a fim de auxiliar profissionais, estudantes e pesquisadores interessados pela temática a ampliarem 
seus conhecimentos acerca dessa problemática, facilitando novas pesquisas e apontando novas demandas desta categoria profissional. O número de publicações focadas no trabalhador bancário, especialmente em suas vivências de sofrimento, é bastante significativo, porém identificou-se carência de estudos focados no apoio e em programas que possam intervir ou problematizar a organização do trabalho e seus efeitos sobre a saúde mental dos trabalhadores.

\section{REFERÊNCIAS}

Alves, G. (2013, Julho 22). O que é o precariado [Postagem no blog da Boitempo]. Recuperado de http://blogdaboitempo.com. br/2013/07/22/o-que-e-o-precariado/

Antunes, R. (2011). Os modos de ser da informalidade: Rumo a uma nova era da precarização estrutural do trabalho? Serviço Social e Sociedade, 107, 405-419. doi: 10.1590/S0101-66282011000300002

Araújo, A. M. C., Cartoni, D. M., \& Justo, C. R. D. M. (2001). Reestruturação produtiva e negociação coletiva nos 90 . Revista Brasileira de Ciências Sociais, 16(45), 85-112.

Associação de Pessoal da Caixa Econômica Federal. (2011). Bancários adoecem mais que outros trabalhadores. Revista Espaço, 76. Recuperado de http://www.apcefsp.org.br/ftp/sp/espaco76/index.html\#/8

Borsoi, I. C. F., Santos, A. O. R., \& Acário, S. H. A. (2006). Trabalhadores amedrontados, envergonhados e (in)válidos: Violência e humilhação nas políticas de reabilitação por LER/DORT. Revista Psicologia Política, 6(12), 1-15.

Brandão, A. G., Horta, B. L., \& Tomasi, E. (2005). Sintomas de distúrbios osteomusculares em bancários de Pelotas e região: Prevalência e fatores associados. Revista Brasileira de Epidemiologia, 8(3), 295-305. doi: 10.1590/S1415$790 \times 2005000300011$

Carrijo, D. C. M., \& Navarro, V. L. (2009). LER e planos de demissão voluntária: Trajetórias de dor e sofrimento entre bancários. Cadernos de Psicologia Social do Trabalho, 12(2), 157-171.

Central Única dos Trabalhadores. (2014, Agosto). Bancários estão entre as categorias que mais adoecem no país. Recuperado de http://cut.org.br/noticias/bancarios-estao-entre-as-categorias-que-mais-adoecem-no-pais-48ac/

Chesnais, F. (1995). A globalização e o curso do capitalismo de fim de século. Economia e Sociedade, 5, 1-30.

Dantas, J. A., Medeiros, O. R., \& Paulo, E. (2011). Relação entre concentração e rentabilidade no setor bancário brasileiro. Revista Contabilidade \& Finanças, 22(55), 5-28.

Faria, G. S. S., \& Rachid, A. (2007). Equilíbrio trabalho e família: Os significados para os bancários. Revista Psicologia: Organizações e Trabalho, 7(1), 81-106.

Ferreira, M. C., \& Seidl, J. (2009). Mal-estar no trabalho: Análise da cultura organizacional de um contexto bancário brasileiro. Psicologia: Teoria e Pesquisa, 25(2), 245-254.

Finazzi-Santos, M. A., \& Siqueira, M. V. S. (2011). Considerações sobre trabalho e suicídio: Um estudo de caso. Revista Brasileira de Saúde Ocupacional, 36(123), 71-83.

Garcia, A., \& Souza, E. M. (2010). Sexualidade e trabalho: Estudo sobre a discriminação de homossexuais masculinos no setor bancário. Revista de Administração Pública, 44(6), 1353-1377. doi: 10.1590/\$0034-76122010000600005

Gravina, M. E. R., \& Rocha, L. E. (2006). Lesões por esforços repetitivos em bancários: Reflexões sobre o retorno ao trabalho. Cadernos de Psicologia Social do Trabalho, 9(2), 41-55.

Grisci, C. L. I., Cigerza, G. C., Hofmeister, P. M., \& Becker, J. L. (2006). Nomadismo involuntário na reestruturação produtiva do trabalho bancário. Revista de Administração de Empresas, 46(1), 27-40.

Junior, A. V. S., Mendes, A. M., \& Araujo, L. K. R. (2009). Experiência em clínica do trabalho com bancários adoecidos por LER/ DORT. Psicologia: Ciência e Profissão, 29(3), 614-625.

Larangeira, S. M. G. (1997). Reestruturação produtiva no setor bancário: A realidade nos anos 90. Educação \& Sociedade, 61, 110-138.

Lima, F. B. (2004). Stress, qualidade de vida, prazer e sofrimento no trabalho de call center (Dissertação de mestrado). Recuperado de http://www.bibliotecadigital.puc-campinas.edu.br/tde_busca/arquivo.php?codArquivo=233

Lima, C. Q. B., Barbosa, C. M. G., Mendes, R. W. B., \& Patta, C. A. (2014). Assédio moral e violências no trabalho: Caracterização em perícia judicial. Relato de experiência no setor bancário. Revista Brasileira de Saúde Ocupacional, 39(129), 101-110. doi: 10.1590/0303-7657000050313 
Linhares, A. R. P., \& Siqueira, M. V. S. (2014). Vivências depressivas e relações de trabalho: Uma análise sob a ótica da psicodinâmica do trabalho e da sociologia clínica. Cadernos EBAPE.BR, 12(3), 719-740. doi: 10.1590/1679-395110385

Linhart, D. (2015, Maio 22). L'entreprise de dépossession [Entrevista com Daniéle Linhart]. Recuperado de http://www. laviedesidees.fr/L-entreprise-de-depossession-3054.html

Maciel, R. H., Cavalcante, R., Matos, T. G. R., Rodrigues, S. (2007). Auto relato de situações constrangedoras no trabalho e assédio moral nos bancários: Uma fotografia. Psicologia \& Sociedade, 19(3), 117-128. doi: 10.1590/S010271822007000300016

Maciel, R. H., Medeiros, S. R., Neves, L. S., Hora, A., Bitu, F. G., \& Souza, T. C. F. (2006). Relatório de pesquisa assédio moral no trabalho: Impactos sobre a saúde dos bancários e sua relação com gênero e raça. Recuperado de http://www. bancariospe.org.br/assedio/relatorio_final.pdf

Mendes, J. M. R., Wunsch, D. S. (2011). Serviço social e a saúde do trabalhador: Uma dispersa demanda. Serviço Social e Sociedade, 107, 461-481. doi: 10.1590/S0101-66282011000300005

Mergener, C. R., Kehrig, R. T., \& Traebert, J. (2008). Sintomatologia músculo-esquelética relacionada ao trabalho e sua relação com qualidade de vida em bancários do meio oeste catarinense. Saúde e Sociedade, 17(4), 171-181.

Ministério da Previdência Social. (2014). Saúde e segurança do trabalho: Estudo da previdência social indica mudança nas causas de afastamento do trabalho. Recuperado de http://www.previdencia.gov.br/noticias/saude-e-seguranca-do-trabalhoestudo-da-previdencia-social-indica-mudanca-nas-causas-de-afastamento-do-trabalho/. [link original].

Mota, A. B., Amaral, A. S. (2000). Reestruturação do capital, fragmentação do trabalho e Serviço Social. In A. E. Mota (Org.), $A$ nova fábrica de consensos: Ensaios sobre reestruturação empresarial, o trabalho e as demandas ao serviço social (2a ed. pp. 23-44). São Paulo: Cortez.

Murofuse, N. T., \& Marziale, M. H. P. (2001). Mudanças no trabalho e na vida de bancários portadores de lesões por esforços repetitivos: LER. Revista Latino-Americana de Enfermagem, 9(4), 19-25. doi: 10.1590/S0104-11692001000400004

Oliveira, M. S. (2010). Adoecimento físico e mental nos bancários (Trabalho de conclusão de curso de graduação). Recuperado de https://www.lume.ufrgs.br/bitstream/handle/10183/72221/000883156.pdf?sequence=1

Olivier, M., Perez, C. S., \& Behr, S. C. F. (2011). Trabalhadores afastados por transtornos mentais e de comportamento: O retorno ao ambiente de trabalho e suas consequências na vida laboral e pessoal de alguns bancários. Revista de Administração Contemporânea, 15(6), 993-1015.

Oltramari, A. P., Grisci, C. L. I., \& Weber, L. (2011). Carreira e relações familiares: Dilemas de executivos bancários. Revista Mal Estar e Subjetividade, 11(1), 100-133.

Organização Internacional do Trabalho. (2015, Maio). World employment and social outlook: The changing nature of jobs. Recuperado de http://www.ilo.org/global/research/global-reports/weso/2015-changing-nature-of-jobs/WCMS_368626/lang-en/index.htm

Paiva, C. S. D. L., \& Borges, L. O. (2009). O ambiente de trabalho no setor bancário e o bem-estar. Psicologia em Estudo, 14(1), 57-66.

Paparelli, R. (2011). Grupos de enfrentamento do desgaste mental no trabalho bancário: Discutindo sobre saúde mental do trabalhador no sindicato. Revista Brasileira de Saúde Ocupacional, 36(123), 139-146. doi: 10.1590/S030376572011000100013

Pavão, P. (2013). La lucha de los sindicatos de bancarios de Brasil contra el acoso moral. Salud de los Trabajadores, 21(1), 3139.

Petarli, G. B., Salaroli, L. B., Bissoli, N. S., \& Zandonade, E. (2015). Autoavaliação do estado de saúde e fatores associados: Um estudo em trabalhadores bancários. Cadernos de Saúde Pública, 31(4), 787-799.

Resende, S., \& Mendes, A. M. (2004). A sobrevivência como estratégia para suportar o sofrimento no trabalho bancário. Revista Psicologia: Organizações e Trabalho, 4(1), 151-175.

Rocha, S. R. A. (2007). Depressão relacionada aos distúrbios osteomusculares no trabalho bancário. In A. M. Mendes (Org.), Psicodinâmica do trabalho: Teoria, método e pesquisa (pp. 205-230). São Paulo: Casa do Psicólogo.

Santos, M. A. F. (2009). Patologia da solidão: O suicídio de bancários no contexto da nova organização de trabalho (Dissertação de mestrado). Recuperado de http://repositorio.unb.br/handle/10482/4266

Santos, M. A. F., Siqueira, M. V. S., \& Mendes, A. M. (2010). Tentativas de suicídio de bancários no contexto das reestruturações produtivas. Revista de Administração Contemporânea, 14(5), 925-938.

Santos, M. A. F., Siqueira, M. V. S., \& Mendes, A. M. (2011). Sofrimento no trabalho e imaginário organizacional: Ideação suicida de trabalhadora bancária. Psicologia e Sociedade, 23(2), 359-368. 
Schneider, A. M. A., \& Werlang, B. S. G. (2013). Assalto no local de trabalho, personalidade e coping: Uma revisão da literatura. Psicologia Argumento, 31(72), 101-111.

Scopel, J., Oliveira, P. A. B., \& Wehrmeister, F. C. (2012). LER/DORT na terceira década da reestruturação bancária: Novos fatores associados? Revista de Saúde Pública, 46(5), 875-885. doi: 10.1590/S0034-89102012000500015

Silva, J. L., \& Navarro, V. L. (2012). Organização do trabalho e saúde de trabalhadores bancários. Revista Latino Americana de Enfermagem, 20(2), 1-15.

Silva, L. S., \& Barreto, S. M. (2012). Condições estressantes no trabalho e pior auto avaliação de saúde entre bancários. Revista Saúde Pública, 46(3), 407-416. doi: 10.1590/S0034-89102012005000023

Soares, L. R., \& Villela, W. V. (2012). O assédio moral na perspectiva de bancários. Revista Brasileira de Saúde Ocupacional, 37(126), 203-212.

Souza, E. M., Silva, A. R. L., \& Carrieri, A. P. (2012). Uma análise sobre as políticas de diversidade promovidas por bancos. Revista Psicologia e Sociedade, 24(2), 315-326.

Wallerstein, I. (1987). World - Systems analysis. In A. Giddens \& J. Turner, Social theory today (pp. 309-324). Stanford: Stanford University Press.

Weber, L., \& Grisci, C. L. I. (2011). Trabalho imaterial bancário, lazer e a vivência de dilemas pessoais contemporâneos. Revista de Administração Contemporânea, 15(5), 897-917. doi: 10.1590/S1415-65552011000500007 